\title{
Measuring the fracture resistance of hard coatings
}

\author{
S. Liu, ${ }^{1,2}$ J. M. Wheeler, ${ }^{3}$ P. R. Howie, ${ }^{1}$ X. T. Zeng, ${ }^{2}$ J. Michler, ${ }^{3}$ and W. J. Clegg ${ }^{1, a)}$ \\ ${ }^{1}$ Gordon Laboratory, Department of Materials Science and Metallurgy, University of Cambridge, \\ Pembroke St, Cambridge CB2 3QZ, United Kingdom \\ ${ }^{2}$ Singapore Institute of Manufacturing Technology, 71 Nanyang Drive, Singapore 638075 \\ ${ }^{3}$ Laboratory for Mechanics of Materials and Nanostructures, EMPA, Swiss Federal Laboratories \\ for Materials Testing and Research, Feuerwerkerstr. 39, CH-3602 Thun, Switzerland
}

(Received 27 March 2013; accepted 18 April 2013; published online 1 May 2013)

\begin{abstract}
A way of characterizing cracking in a hard coating is described. Microscale double cantilever beams have been made by focused ion beam milling and compressed in situ using a nanoindenter. The method can account for frictional effects and is demonstrated first on single crystals of SiC and GaAs of known toughness, before studying cracking in CrN-based hard coatings. It is found that ultra-fine grained $\mathrm{CrAlN} / \mathrm{Si}_{3} \mathrm{~N}_{4}$ coatings have a toughness approximately twice that of a conventional $\mathrm{CrN}$ coating. Although grain-size effects are still unclear, in situ observations directly show crack interactions with particles of $\mathrm{Cr}$ and voids in the film. (C) 2013 AIP Publishing LLC. [http://dx.doi.org/10.1063/1.4803928]
\end{abstract}

The development of hard coatings has generally been based on increasing the hardness or the ratio of the hardness to the Young modulus. ${ }^{1}$ However, in more extreme applications, failure occurs by cracking, so the fracture toughness can influence the lifetime of a coating. ${ }^{2}$

Existing methods for measuring the toughness of a coating have recently been reviewed. ${ }^{3}$ The most straightforward is nanoindentation, ${ }^{4}$ but the numerical constants required must be obtained empirically. ${ }^{4}$ This has led to the development of alternative methods, which include bulge, ${ }^{5}$ tensile ${ }^{6}$ and bend testing of notched beams, ${ }^{7-9}$ as well as fragmentation $^{10}$ and scratching. ${ }^{11}$

Most of these methods require free-standing portions of film that are normally obtained using silicon substrates and photolithography. 5,9 Otherwise, the coating must be separated from the substrate, typically by undercutting using focused ion beam milling (FIB). Such samples normally have a more complex shape, ${ }^{7}$ so that the geometry of the cantilever cross-section must be accurately known to calculate reliable values of the stress intensity factor.

As cracking in tension and bending is catastrophic, it is difficult to study processes associated with cracking, such as bridging or plasticity, by these methods. Stable cracking is associated with double cantilever beam (DCB) geometries, where a moment is applied to each of the beams, on either side of the growing crack. ${ }^{12}$ In single crystals, it has been shown that a situation approaching wedging can be achieved, if the dislocations move on two intersecting slip systems, nucleating a crack, which then grows on further loading. ${ }^{13}$ However, this is hardly a general technique.

One way of overcoming these difficulties is to use a sample of the geometry shown in Fig. 1, where a small strut is machined in each of the beams. When the load is applied by a large flat punch in a nanoindenter, the applied force on each of the beams cannot act along the neutral axis of each of the beams on each side of the crack, so that a moment is

\footnotetext{
${ }^{\text {a) }}$ Author to whom correspondence should be addressed. Electronic mail: wjc1000@cam.ac.uk.
}

applied to each beam. Furthermore, the loading and sample geometry can be determined prior to cracking without the need to determine features such as the loading points on a cantilever.

The aim of this paper is to determine whether such a test might be used to characterize cracking in thin films, as well as the limitations and advantages of such a technique.

Testing was carried out initially on a $\mathrm{SiC}$ crystal, made by the Acheson process and several millimetres in size, and a $\langle 100\rangle$-oriented GaAs wafer, and then on $\mathrm{CrN}$ and $\mathrm{CrAlSiN}$ hard coatings. The coatings were deposited on Inconel 718 alloy substrates by a laterally rotating cathodic arc deposition system (Platit $\pi^{80}$, Switzerland), described fully elsewhere. ${ }^{14}$ The as-deposited coatings were about $6 \mu \mathrm{m}$ in thickness, and were lightly polished.

Micro DCBs, Fig. 1, were prepared by focused ion beam milling (Helios NanoLab, FEI Company, Netherlands). Rectangular pillars with a nominal height of $2-4 \mu \mathrm{m}$ were coarsely milled with high current $\mathrm{Ga}^{+}$ion beams $(30 \mathrm{keV}$, $6.5 \mathrm{nA}$ and $2.7 \mathrm{nA}$ ) to define the outline of the micro DCB, followed by a fine cut at lower beam current $(30 \mathrm{keV}, 90 \mathrm{pA}$ to $0.9 \mathrm{nA})$ at $1.5^{\circ}$ from the vertical to remove the wall tapering. In the $\mathrm{SiC}$ and $\mathrm{GaAs}$ crystals, the pillar axes were parallel to $\langle 0001\rangle$ and $\langle 100\rangle$, respectively. Subsequently, the shoulders of the micro DCBs were created by milling the middle section of

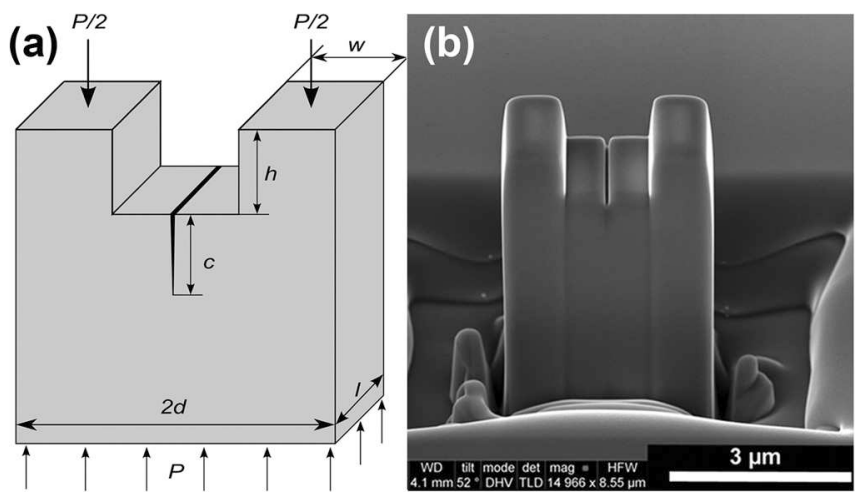

FIG. 1. Schematic and SEM picture of a SiC double cantilever beam. 
the top surface at a low beam current $(30 \mathrm{keV}, 90 \mathrm{pA})$. Finally, a pre-crack, deeper than that of any FIB damage, was introduced to the centre of the top surface by an even finer beam $(30 \mathrm{keV}, 26 \mathrm{pA})$. Before and after each compression experiment, the micro DCBs were imaged in a field emission scanning electron microscope at a tilt angle of $52^{\circ}$, so the sample deformation and crack elongation could be studied.

The DCBs were compressed using either an in situ nanoindenter ${ }^{15}$ (Alemnis) with a $5 \mu$ m diameter diamond punch, at displacement rates of $1 \mathrm{~nm} \mathrm{~s}^{-1}$ to $5 \mathrm{~nm} \mathrm{~s}^{-1}$ or, in the case of the GaAs crystal, a conventional nanoindenter (MTS Nanoindenter XP) with a $10 \mu \mathrm{m}$ diameter diamond punch. To minimize any difficulties from debris on the sample surface, the sample was first strained elastically and the punch withdrawn, before restraining until cracking occurred, followed by unloading. To study the effects of friction and plastic deformation of the DCB shoulders, the cracked DCB sample was strained again up to the same load, so that there was no further crack extension.

The fracture toughness of the sample can be estimated from the compression load at crack extension. Consider a sample of Young modulus $E$, with a thickness $b$, in the direction parallel to the plane of the crack and width $2 d$, where the distance from the top of the sample to the tip of the crack is $h$. Applying an overall compressive load, $P$, gives rise to a moment $M_{\mathrm{B}}$ on each beam, as in Fig. 1, given by $M_{\mathrm{B}}=P e / 2$, where $e$, the distance between the line of action of $P$ and the neutral axis of the beam, is given by $e=(d-w) / 2$. However, friction between the punch and the struts will give rise to a moment, $M_{\mathrm{f}}=-P \mu h / 2$, where $\mu$ is the coefficient of friction between the punch and the sample, so that the overall moment, $M$ is

$$
M=\frac{P}{2}(e-\mu h) .
$$

The strain energy release rate, $G$, is

$$
G=\frac{M^{2}}{E I_{x} b},
$$

where the second moment of area, $I_{x}=b d^{3} / 12$. Substituting for $M$ and $I_{x}$ gives

$$
G=3 P^{2} \frac{(e-\mu h)^{2}}{E b^{2} d^{3}}
$$

Using $E R=K_{\mathrm{IC}}^{2}$, where $R$ is the fracture resistance, with Eq. (3), the fracture toughness, $K_{\mathrm{IC}}$, can be expressed in terms of the load at which cracking starts, $P_{\mathrm{C}}$, as

$$
K_{\mathrm{IC}}=\sqrt{3} \frac{(e-\mu h)}{b d^{3 / 2}} P_{\mathrm{C}} .
$$

A typical load-displacement curve from the compression of the single-crystal $\mathrm{SiC}$ and GaAs micro DCBs is shown in Fig. 2. In situ tests showed that, after some initial bedding down of the sample, the onset of crack extension was associated with a sudden load drop, after which the crack propagated stably as the sample was further compressed. There, resulting increase in the sample compliance after cracking can also be

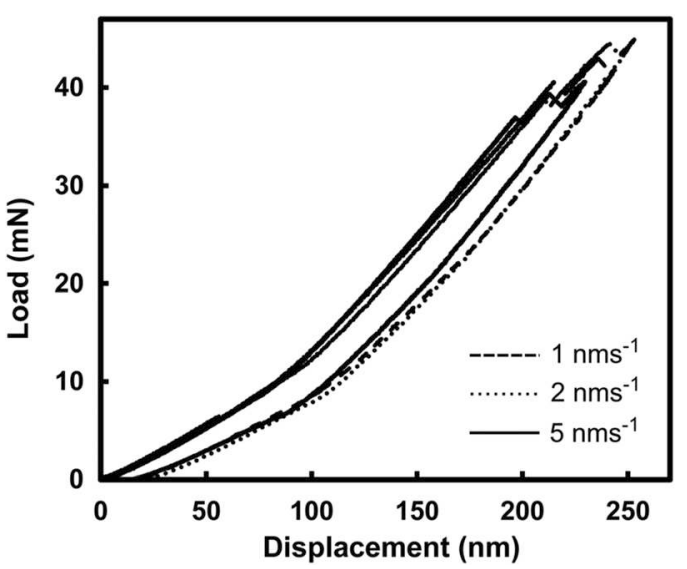

FIG. 2. Load/displacement curves from SiC micro DCB compressions.

seen. Using the measured values for the sample dimensions, $P_{\mathrm{C}}$ from the load-displacement curve and $\mu=0.08,{ }^{16}$ a value for $K_{\mathrm{IC}}$ of $3.6 \pm 0.1 \mathrm{MPa} \sqrt{ } \mathrm{m}$ is obtained for the $14 \mathrm{SiC}$ micro DCBs regardless of the displacement rate. This compares with a value of $3.3 \mathrm{MPa} \vee \mathrm{m}$ in the literature. ${ }^{17}$

For GaAs, the friction coefficients are less well known. Measurements of GaAs sliding on metals give values between 0.15 and $0.25 .{ }^{18}$ As one might expect a lower friction coefficient with diamond, the value of 0.15 was used. This gives a fracture toughness of $0.57 \mathrm{MPa} \sqrt{\mathrm{m}}$, within the range of $0.43-0.98 \mathrm{MPa} \sqrt{ } \mathrm{m}$ observed. ${ }^{19}$ Yielding of the struts was observed in some GaAs DCBs. Fig. 3(a) shows the slip bands formed by yielding during cracking in a DCB with a width of approximately $0.8 \mu \mathrm{m}$. If this occurred, a load drop could not be seen on the load/displacement plot, with the onset of non-linear behaviour starting at a load that would correspond to a stress in each strut of approximately 2.5 GPa, consistent with observations elsewhere. ${ }^{13}$ However, no plastic deformation was observed in a DCB, where the strut width was about $1.7 \mu \mathrm{m}$, Fig. 3(b). Yielding will occur when the load in the strut reaches $P_{\mathrm{Y}}$, which is given by $P_{\mathrm{Y}}=2 w d \sigma_{\mathrm{Y}}$, where $\sigma_{\mathrm{Y}}$ is the yield stress of the material. To avoid yielding the load, $P_{C}$ required for crack extension must be less than $P_{\mathrm{Y}}$, i.e.,

$$
\frac{K_{\mathrm{IC}}}{\sigma_{\mathrm{Y}}}<\sqrt{3}\left(w d^{-1 / 2}-w^{2} d^{-3 / 2}\right)
$$

The maximum value of $\left(w d^{-1 / 2}-w^{2} d^{-3 / 2}\right)$ is where $w=d / 2$. Substituting for $w$ in terms of $d$ gives

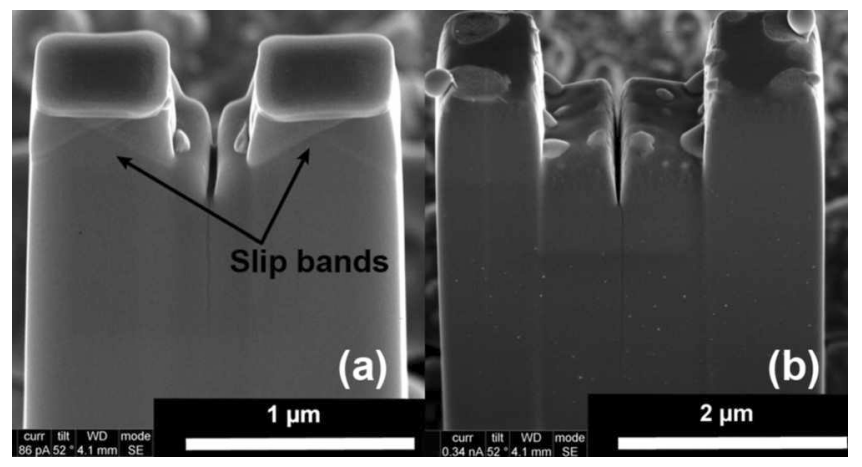

FIG. 3. Size effects of micro DCB compression: (a) yielding in smaller GaAs struts with slip bands (arrowed), while (b) larger struts remain elastic. 


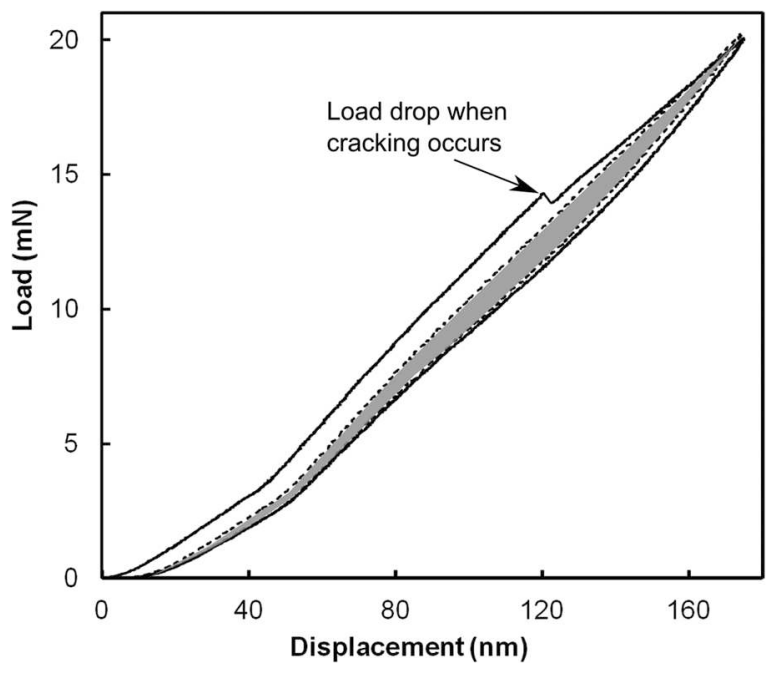

FIG. 4. Load/displacement curve for $\mathrm{CrN}$ hard coating, showing reversible hysteresis loop.

$$
\frac{K_{\mathrm{IC}}}{\sigma_{\mathrm{Y}}}<\frac{\sqrt{3}}{4} \sqrt{d} .
$$

The above equation gives the maximum ratio of the fracture toughness to the yield stress for a given size of pillar that will enable the toughness to be measured without simultaneous plastic flow.

The method was also used to study the cracking behaviour in $\mathrm{CrN}$ and $\mathrm{CrAlN} / \mathrm{Si}_{3} \mathrm{~N}_{4}$ coatings. A fully reversible hysteresis was observed, shown in Fig. 4, if the sample was loaded a second time and unloaded for a second time. As no crack growth or yielding was observed, this was associated with work done against friction between the punch and the sample. To estimate the friction coefficient, the lateral displacements were measured from a video taken during a reloading experiment carried out in situ, Fig. 5(a). The distance between the protruding sections at the top of the pillar was measured in several positions and averaged, Fig. 5(b), giving the lateral displacement of the top portion of the pillar.

The scatter has a magnitude of 1-2 pixels on the SEM images and is believed to be an artefact of the measurement process. It was therefore supposed that the pillar halves were stationary until friction was overcome, after which they moved at an approximately constant velocity during both loading and unloading.

To correlate force and lateral displacement values, it was assumed that the maximum load coincided with the start
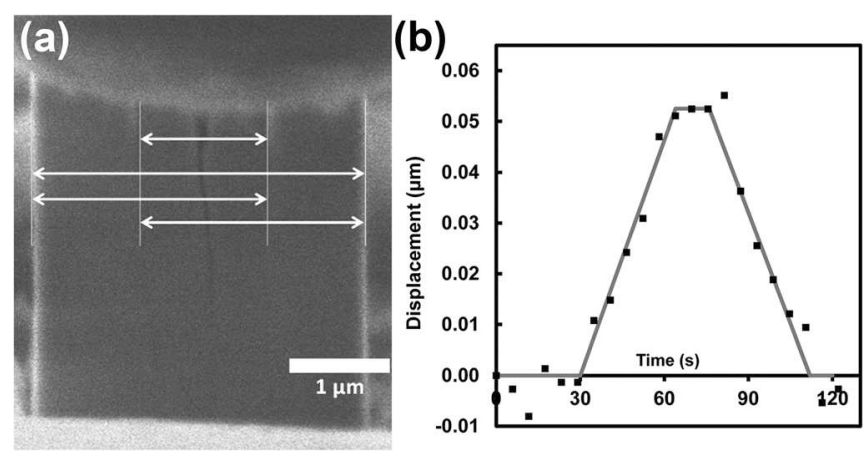

FIG. 5. (a) Lateral displacements measured from SEM video and (b) change in lateral sample displacements with test time.

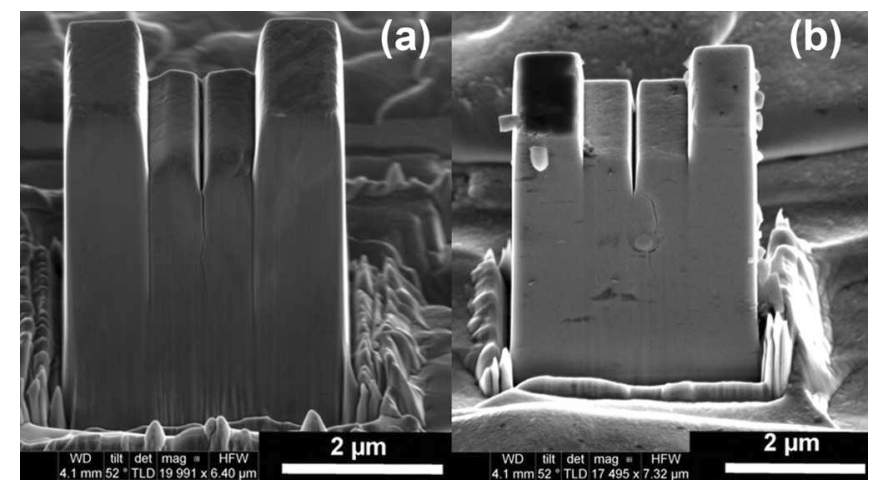

FIG. 6. Cracking in micro DCBs made from (a) CrN coating and (b) CrAlN/ $\mathrm{Si}_{3} \mathrm{~N}_{4}$ coating.

of the plateau at maximum lateral displacement. This gives the total work done as

$$
W_{\mathrm{T}}=\mu \int P(t) x(t) \mathrm{d} t
$$

Setting this equal to the area inside the hysteresis loop, $E_{\mathrm{H}}$, Fig. 4, the coefficient of friction is

$$
\mu=\frac{E_{\mathrm{H}}}{\int P(t) x(t) \mathrm{d} t} .
$$

This gives $\mu=0.09$ for the $\mathrm{CrN}$ film tested. Literature values for diamond rubbing against $\mathrm{CrN}$ vary between 0.05 and $0.2 .^{20}$

Using Eq. (4) and knowing the coefficient of friction, the toughness of the columnar $\mathrm{CrN}$ coatings was estimated to be $1.75 \pm 0.07 \mathrm{MPa} \sqrt{\mathrm{m}}$, whereas that of the very fine grained $\mathrm{CrAlN} / \mathrm{Si}_{3} \mathrm{~N}_{4}$ coating was $3.26 \pm 0.35 \mathrm{MPa} \sqrt{\mathrm{m}}$, almost twice as great. The effect of grain-size on cracking is not yet understood. However, the greater scatter in the measured values for the tougher coating was attributed to the greater microstructural variability in the $\mathrm{CrAlN} / \mathrm{Si}_{3} \mathrm{~N}_{4}$ coating, as in situ studies of cracking showed that the cracks were deflected at Cr-rich inclusions, Fig. 6, and voids in the coating, which were not observed in the $\mathrm{CrN}$ coating. This demonstrates that the method can be used both to study how cracking occurs in such films and to give reliable measurements of the fracture toughness.

A microscale method is demonstrated for measuring the fracture toughness and studying the nature of cracking in a hard coating. The method is tested in crystals of SiC and GaAs and gives reproducible and quantitatively reliable results. The significance of friction is quantified and a protocol to account for it established using in situ testing. Using CrN-based hard coatings, it was found that the fracture toughness of the fine-grained $\mathrm{CrAlN} / \mathrm{Si}_{3} \mathrm{~N}_{4}$ coating was almost a factor of two greater than that of a conventional $\mathrm{CrN}$ coating, and that cracks were associated with defects in the film, showing that the method can be used to measure the toughness and to study cracking in different coatings.

This research was funded by A*STAR, Singapore and the Engineering and Physical Sciences Research Council 
(EPSRC) and Rolls Royce Strategic Partnership "Structural Metallic Systems for Advanced Gas Turbine Applications" (EP/H500375/1).

${ }^{1}$ S. Veprek, Eur. Phys. J.: Appl. Phys. 28, 313 (2004).

${ }^{2}$ P. K. Wright and E. M. Trent, Metal Cutting (Butterworth-Heinemann, 2000).

${ }^{3}$ S. Zhang, D. Sun, Y. Fu, and H. Du, Surf. Coat. Technol. 198, 74 (2005).

${ }^{4}$ S. Zhang and X. Zhang, Thin Solid Films 520, 2375 (2012).

${ }^{5}$ B. Merle and M. Göken, Acta Mater. 59, 1772 (2011).

${ }^{6}$ S. Zhang, D. Sun, Y. Fu, and H. Du, Thin Solid Films 469-470, 233 (2004).

${ }^{7}$ D. Di Maio and S. G. Roberts, J. Mater. Res. 20, 299 (2005).

${ }^{8}$ K. Matoy, H. Schönherr, T. Detzel, and G. Dehm, Thin Solid Films 518, 5796 (2010); F. Iqbal, J. Ast, M. Göken, and K. Durst, Acta Mater. 60, 1193 (2012).

${ }^{9}$ K. Matoy, H. Schönherr, T. Detzel, T. Schöberl, R. Pippan, C. Motz, and G. Dehm, Thin Solid Films 518, 247 (2009).

${ }^{10}$ E. Harry, A. Rouzaud, M. Ignat, and P. Juliet, Thin Solid Films 332, 195 (1998).

${ }^{11}$ K. Holmberg, A. Laukkanen, H. Ronkainen, K. Wallin, and S. Varjus, Wear 254, 278 (2003).
${ }^{12}$ B. R. Lawn, Fracture of Brittle Solids, 2nd ed. (Cambridge University Press, Cambridge, 1993).

${ }^{13}$ F. Östlund, P. R. Howie, R. Ghisleni, S. Korte, K. Leifer, W. J. Clegg, and J. Michler, Philos. Mag. 91, 1190 (2011).

${ }^{14}$ X. Ding, X. T. Zeng, and Y. C. Liu, Thin Solid Films 519, 1894 (2011).

${ }^{15}$ J. M. Wheeler and J. Michler, Rev. Sci. Instrum. 84, 045103 (2013).

${ }^{16}$ M. N. Gardos and K. V. Ravi, in Proceedings of the First International Symposium on Diamond and Diamond-Like Films, edited by J. P. Dismukes (The Electrochemical Society, Tokyo, Japan, 1989), Vol. 89, p. 1.

${ }^{17}$ W. W. Gerberich, W. M. Mook, C. B. Carter, and R. Ballarini, Int. J. Fract. 148, 109 (2007).

${ }^{18}$ H. Mishina and D. H. Buckley, Effect of Barrier Height on Friction Behavior of the Semiconductors Silicon and Gallium Arsenide in Contact with Pure Metals (National Aeronautics and Space Administration, Scientific and Technical Information Branch, Washington, D.C., 1984).

${ }^{19}$ R. W. Margevicius and P. Gumbsch, Philos. Mag. A 78, 567 (1998).

${ }^{20}$ G. Wei, T. W. Scharf, J. N. Zhou, F. Huang, M. L. Weaver, and J. A. Barnard, Surf. Coat. Technol. 146-147, 357 (2001); J.-W. Lee and J.-G. Duh, ibid. 188-189, 655 (2004). 